\title{
Implications of NOVA1 suppression within the microenvironment of gastric cancer: association with immune cell dysregulation
}

\author{
Eun Kyung Kim ${ }^{1} \cdot$ Sun Och Yoon ${ }^{1}$ Woon Yong Jung ${ }^{2} \cdot$ Hyunjoo Lee $^{3} \cdot$ \\ Youngran Kang ${ }^{2}$ - You-Jin Jang ${ }^{4} \cdot$ Soon Won Hong ${ }^{1} \cdot$ Seung Ho Choi ${ }^{5}$ • \\ Woo Ick Yang ${ }^{1}$
}

Received: 22 February 2016/Accepted: 8 June 2016/Published online: 18 June 2016

(c) The International Gastric Cancer Association and The Japanese Gastric Cancer Association 2016

\begin{abstract}
Background The neuronal splicing factor neuro-oncological ventral antigen 1 (NOVA1) is enriched in normal fibroblasts. Stromal spindle cells such as fibroblasts are major components of tissue inflammation and tertiary lymphoid structures within the microenvironment that contribute to the survival and growth of cancer cells. In the present study, we investigated changes of NOVA1 expression in tertiary lymphoid structures in early and advanced gastric cancer microenvironments in terms of tumor progression and immune regulation.

Methods Using immunohistochemistry, we analyzed NOVA1 expression in tumor cells, $\mathrm{T}$ cells, and stromal spindle cells as well as infiltrating densities of $\mathrm{CD}^{+} \mathrm{T}$ cells, forkhead box $\mathrm{P} 3$ positive $\left(\mathrm{FOXP} 3^{+}\right)$regulatory $\mathrm{T}$ cells, $\mathrm{CD} 68^{+}$macrophages, $\mathrm{CD} 163^{+} \mathrm{M} 2$ macrophages, and
\end{abstract}

Electronic supplementary material The online version of this article (doi:10.1007/s10120-016-0623-3) contains supplementary material, which is available to authorized users.

Sun Och Yoon

soyoon@yuhs.ac; revita@naver.com

1 Department of Pathology, Yonsei University College of Medicine, 50-1 Yonsei-ro, Seodaemun-gu, Seoul 120-752, Korea

2 Department of Pathology, Korea University Guro Hospital, Korea University College of Medicine, Seoul, Korea

3 Department of Pathology, Kangbuk Samsung Hospital, Sungkyunkwan University College of Medicine, Seoul, Korea

4 Department of Surgery, Korea University Guro Hospital, Korea University College of Medicine, Seoul, Korea

5 Department of Surgery, Yonsei University College of Medicine, Seoul, Korea myeloperoxidase-positive neutrophils in 396 surgically resected gastric cancer tissues.

Results Suppressed NOVA1 expression in tumor cells, T cells, and stromal spindle cells was closely related to decreased infiltration of $\mathrm{FOXP}^{+}$regulatory $\mathrm{T}$ cells, increased infiltration of $\mathrm{CD} 68^{+}$macrophages and $\mathrm{CD} 163^{+}$ M2 macrophages, more advanced tumor stage, and inferior overall survival rate. In addition, low infiltration of $\mathrm{CD}^{+}$ $\mathrm{T}$ cells and $\mathrm{FOXP}^{+}$regulatory $\mathrm{T}$ cells and high infiltration of $\mathrm{CD} 68^{+}$macrophages were associated with inferior overall survival. Specifically, weak NOVA1 expression in tumor cells was independently related to more advanced tumor stage and inferior overall survival.

Conclusions NOVA1 suppression was frequently noted in the gastric cancer microenvironment, and attenuated NOVA1 expression in tumor cells was associated with tumor progression and poor prognosis. This finding seems to be related to immune dysfunction through changes in the immune cell composition of $\mathrm{T}$ cells and macrophages.

Keywords Neuro-oncological ventral antigen 1 - Immune dysregulation - Microenvironment - Gastric cancer

\section{Introduction}

The microenvironment contributes to the survival and growth of cancer cells. Tumor growth involves coevolutionary processes among tumor cells, extracellular matrix, vasculatures, and immune cells [1]. Cancer-associated inflammation or tertiary lymphoid structures made by ectopically accumulated immune lymphoid cells and matrix components are formed within the tumor microenvironment as an immune reaction in response to stimuli of tumor growth [1-5]. 
Neuro-oncological ventral antigen 1 (NOVA1) is involved in the neuronal splicing program [6-9]. A recent study revealed that NOVA1 is enriched in normal fibroblasts, suggesting involvement in the splicing programs of normal fibroblasts [10]. We previously noted that NOVA1 is expressed in only a small number of $\mathrm{T}$ cells within normal physiologic secondary lymphoid structures such as the palatine tonsils [11] . On the other hand, it is strongly upregulated in the accumulated $\mathrm{T}$ cells and fibroblasts/stromal spindle cells/reticular support cells of the tissue matrix within benign inflammatory tissue of the stomach such as in chronic gastritis or Helicobacter gastritis (Fig. S1). Given that stromal spindle cells such as fibroblasts are major components of tissue inflammation or tertiary lymphoid structures within the microenvironment [1-3] and that these cells actively regulate immune cells in the inflammatory process [1], NOVA1 seems to be induced in ectopically accumulated $\mathrm{T}$ cells via active interaction with stromal spindle cells during the immune response or inflammatory processes [11]. However, in cancer-associated inflammation or tertiary lymphoid structures, NOVA1 expression is frequently suppressed in $\mathrm{T}$ cells within the gastric cancer microenvironment, and that suppression correlates with poor survival in advanced gastric cancer patients [11].

In the present study, we extended the previous findings and robustly investigated NOVA1 expression in large numbers of early and advanced gastric cancer tissues. We evaluated changes in NOVA1 expression according to tumor progression from the early to the advanced stage and associated clinicopathologic implications. In particular, the association between NOVA1 expression and immune cell regulation within the tumor microenvironment was analyzed.

\section{Materials and methods}

\section{Patients and clinical data}

Archived formalin-fixed, paraffin-embedded tissues were obtained from 396 patients with gastric carcinoma. Among them, 146 had early gastric cancer and 250 had advanced gastric cancer. Standard resection with curative intent was performed at Korea University Guro Hospital from 2002 to 2005. No preoperative treatment was performed. According to tumor stage, $96 \%$ (62\% of all the patients studied) of the indicated patients received postoperative 5-fluorouracil-based adjuvant chemotherapy. The mean follow-up period was 50.3 months (median 53.9 months; range $0-84.5$ months). Clinicopathologic data were obtained from medical records and the histopathologic features of all patients were reviewed by pathologists. Tumors were classified according to the seventh American Joint Committee on Cancer (AJCC) TNM cancer classification system, the World Health Organization classification, and the Japanese classification [12-14]. The clinicopathologic characteristics of the patients are described in Table 1. The institutional review board of our institution approved this study.

\section{Tissue microarray preparation and immunohistochemistry}

Sections of formalin-fixed, paraffin-embedded tissues were prepared and stained with hematoxylin and eosin. Under

Table 1 Characteristics of gastric cancer patients

\begin{tabular}{|c|c|c|}
\hline \multirow[t]{2}{*}{ Characteristic } & \multicolumn{2}{|c|}{ Patients } \\
\hline & $n$ & $\%$ \\
\hline All patients & 396 & \\
\hline \multicolumn{3}{|l|}{ Sex } \\
\hline Male & 270 & 68.2 \\
\hline Female & 126 & 31.8 \\
\hline \multicolumn{3}{|l|}{ Age (years) } \\
\hline$\leq 60$ & 195 & 49.2 \\
\hline$>60$ & 201 & 50.8 \\
\hline \multicolumn{3}{|l|}{ Histologic type } \\
\hline Differentiated & 199 & 50.3 \\
\hline Undifferentiated & 197 & 49.7 \\
\hline \multicolumn{3}{|c|}{ Lymphovascular invasion } \\
\hline Absent & 246 & 62.1 \\
\hline Present & 150 & 37.9 \\
\hline \multicolumn{3}{|l|}{ EGC vs AGC } \\
\hline EGC & 146 & 36.9 \\
\hline AGC & 250 & 63.1 \\
\hline \multicolumn{3}{|l|}{ pT category ${ }^{a}$} \\
\hline pT1 & 146 & 36.9 \\
\hline pT2 & 53 & 13.4 \\
\hline pT3 & 58 & 14.6 \\
\hline pT4 & 139 & 35.1 \\
\hline \multicolumn{3}{|l|}{ pN category ${ }^{\mathrm{a}}$} \\
\hline pNO & 192 & 48.5 \\
\hline pN1 & 50 & 12.6 \\
\hline pN2 & 48 & 12.1 \\
\hline $\mathrm{pN} 3$ & 106 & 26.8 \\
\hline \multicolumn{3}{|c|}{ Anatomic stage/prognostic group ${ }^{b}$} \\
\hline I & 165 & 41.7 \\
\hline II & 77 & 19.4 \\
\hline III & 143 & 36.1 \\
\hline IV & 11 & 2.8 \\
\hline
\end{tabular}

$A G C$ advanced gastric cancer, $E G C$ early gastric cancer

a Stomach cancers were staged on the basis of the seventh edition of the AJCC Cancer Staging Manual [12]

b Distant metastases were determined on the basis of Clinicopathologic information at the time of surgery. 
the microscope, representative tumor areas were chosen at the deep invasive front with peritumoral stroma and prepared so as to create a tissue microarray. One or two different regions per case were punched out from donor blocks of $3 \mathrm{~mm}$ in diameter. Immunohistochemistry was performed on 4- $\mu \mathrm{m}$ tissue sections with a Ventana Bench Mark XT Autostainer (Ventana Medical Systems, Tucson, AZ, USA) with NOVA1 (dilution 1:500; Abcam, Cambridge, UK), cytokeratin (clone AE1/AE3; dilution 1:600; DAKO, Glostrup, Denmark), CD68 (dilution 1:150, clone PG-M1; DAKO), CD163 (dilution 1:100; clone MRQ-26; Cell Marque, Rocklin, CA, USA), CD3 (dilution 1:200; LabVision, Fremont, CA, USA), CD4 (dilution 1:200; Cell Marque), myeloperoxidase (MPO; dilution 1:2000, DAKO), and forkhead box P3 (FOXP3; dilution 1:100; Abcam) primary antibodies.

NOVA1 expression was analyzed according to the previously described semiquantitative approach [11, 15]. Staining intensity ( 1 , no staining to weak intensity; 2 , moderate intensity; 3 , strong intensity) was multiplied by the percentage of positive cell nuclei $(1,0-9 \%$; 2 , $10-19 \%$; 3, 20-29\%; 4, 30-39\%; 5, 40-49\%; 6, $50-59 \% ; 7,60-69 \% ; 8,70-79 \% ; 9,80-89 \% ; 10$, 90-100\%). NOVA1 expression was scored from 1 to 30 and classified as strong (score 21-30), moderate (score 11-20), or weak (score 1-10). The expression pattern of NOVA1 was evaluated in tumor cells, stromal spindle cells (fibroblasts, support cells, and endothelial cells), and immune cells (Fig. 1A). Regarding stromal spindle cells and immunes cells, NOVA1 expression was evaluated within the tumor cell nests and invasive tumor front area. Considering that our previous study had found that NOVA1 was expressed only in T cells and not in B cells or macrophages (Fig. S1) [11], we focused on the NOVA1 expression in $\mathrm{T}$ cells by comparing the $\mathrm{CD}^{+}$cells. For indicated cases that showed noncohesive, poorly differentiated histologic features, tumor cells were identified by comparing cytokeratin-positive cells.

\section{Cell density}

Although all tissue cores were confirmed to contain appropriate tumor tissue occupying at least $50 \%$ of the core area, the ratio of epithelial (tumor) area to stromal area differed among tissue cores. Therefore we counted tumorinfiltrating immune cells within the tumor cell nests and invasive tumor front area [16]. Stained slides were scanned with a ScanScope CS system (Aperio Technologies, Vista, CA, USA), and the images were viewed with use of the Aperio ImageScope program (version 11.2.0.782; Aperio Technologies, Vista, CA, USA). The morphology and number of macrophages, $T$ lymphocytes, and neutrophils were assessed by a hematopathologist (S.O.Y.). CD68 ${ }^{+}$ macrophages, $\mathrm{CD}_{163}{ }^{+} \mathrm{M} 2$ macrophages, $\mathrm{CD}^{+} \mathrm{T}$ lymphocytes, $\mathrm{MPO}^{+}$neutrophils, and $\mathrm{FOXP} 3_{+}$regulatory $\mathrm{T}$ cells (Tregs) that infiltrated within the tumor microenvironment were evaluated as follows: The five most representative $\times 400$ magnification high-power fields were selected from the digital immunohistochemistry slides for CD68, CD163, CD3, MPO, and FOXP3. Preserved intact nuclei were counted manually, and the cell numbers were averaged. When the cell density was above the mean value of the overall cases, the sample was defined as high density for that inflammatory cell type (Fig. 1B).

\section{Statistical analysis}

Pearson correlation, one-way ANOVA, $t$, and $\chi^{2}$ tests were used as appropriate to analyze differences between the variables examined. Survival rates were analyzed with the Kaplan-Meier method, and differences were compared with the log-rank test. Overall survival was measured from the date of diagnosis to that of gastric cancer-associated death or the last follow-up visit. Univariate and multivariate analyses were performed with the Cox proportional hazards model. Parameters showing statistical significance $(P<0.05)$ on univariate analysis were included in the multivariate analysis, which was performed with a backward stepwise method. Two-sided $P$ values less than 0.05 were considered statistically significant. Statistical analyses were performed with IBM SPSS Statistics for Windows version 22.0 (IBM, New York, NY, USA).

\section{Results}

\section{Association between NOVA1 expression and immune cell infiltration within the gastric cancer microenvironment}

The distribution of NOVA1 expression in tumor cells, T cells, and stromal spindle cells is presented in Fig. 2A-C. The NOVA1 expression status among tumor cells, T cells, and stromal spindle cells were strongly correlated with each other (correlation coefficient, 0.39-0.53; $P<0.001$; Table S1). Infiltrating densities of $\mathrm{T}$ lymphocytes, macrophages, and neutrophils revealed weak positive linear correlation with each other (Fig. S2a-c). The densities of $\mathrm{FOXP}^{+}{ }^{+}$Tregs and $\mathrm{CD}^{+} \mathrm{T}$ lymphocytes also revealed weak positive linear correlation (Fig. S2d). The densities of $\mathrm{CD}_{163^{+}} \mathrm{M} 2$ macrophages and CD68+ macrophages were also strongly correlated (Fig. S2e). The overall density of infiltrating immune cells (lymphocytes, macrophages, and neutrophils) did not vary according to the NOVA1 status of tumor cells, T cells, and stromal spindle cells. The densities of infiltrating $\mathrm{CD}^{+} \mathrm{T}$ cells or $\mathrm{MPO}^{+}$ 
A

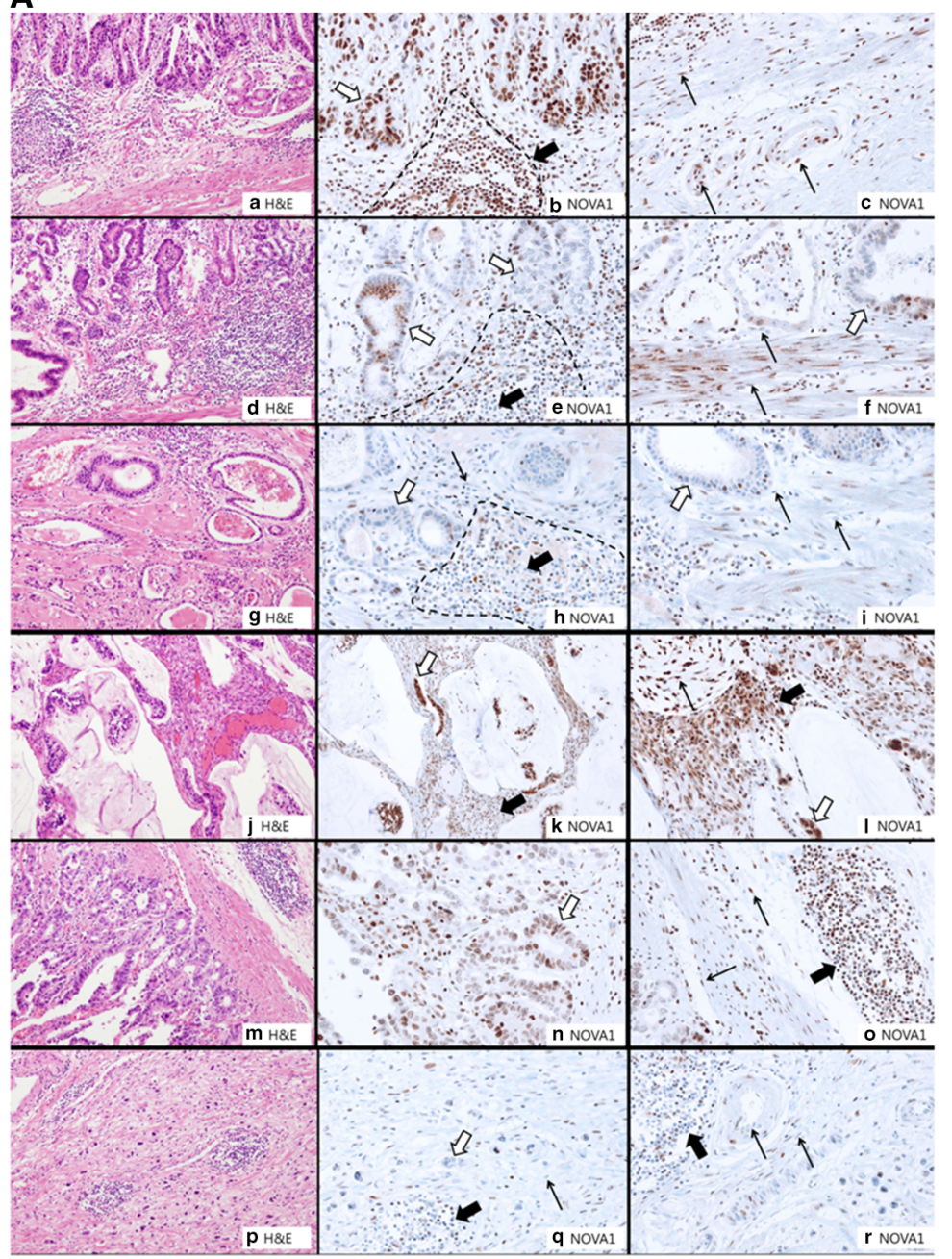

B

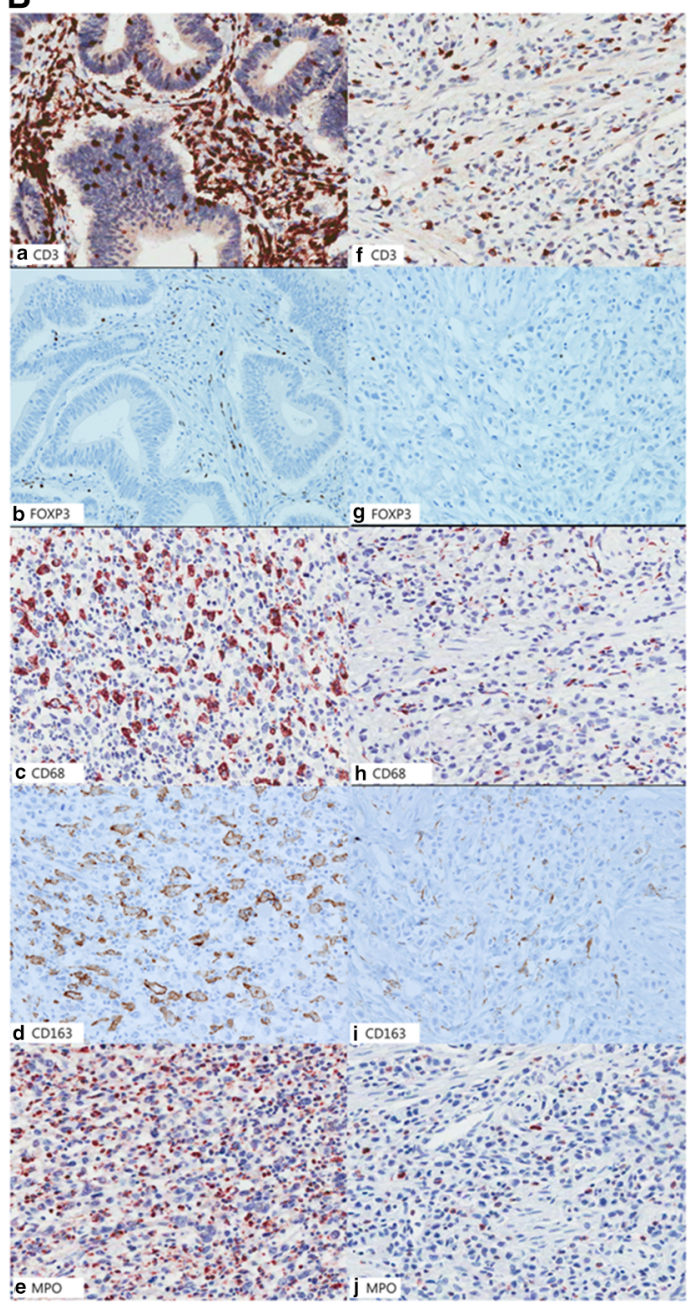

Fig. 1 A Representative cases of neuro-oncological ventral antigen 1 (NOVA1) expression in tumor cells (white arrow), T lymphocytes (thick black arrow and dotted area), and stromal spindle cells (thin black arrow): an early gastric cancer (EGC) case showing strong NOVA1 expression in tumor cells, T cells, and stromal spindle cells $(a-c)$; an EGC case showing weak NOVA1 expression in tumor cells and moderate expression in T cells and stromal spindle cells $(d-f)$; an EGC case showing weak NOVA1 expression in tumor cells, T cells, and stromal spindle cells $(g-i)$; an advanced gastric cancer (AGC) case showing strong NOVA1 expression in tumor cells, T cells, and spindle cells $(j-l)$; an AGC case showing moderate NOVA1

neutrophils $\left(\mathrm{MPO}^{+}\right.$polymorphonuclear cells) were not significantly altered according to the NOVA1 status of tumor cells, T cells, and stromal spindle cells (Fig. S3).

Although the density of infiltrating $\mathrm{CD}^{+} \mathrm{T}$ cells was not significantly different according to NOVA1 expression status, the density of $\mathrm{FOXP}^{+}$Tregs was higher when the NOVA1 expression level increased in T cells, tumor cells, and stromal spindle cells (Fig. 2D-F). In contrast, the densities of $\mathrm{CD}^{+} 8^{+}$macrophages and $\mathrm{CD}_{163^{+}} \mathrm{M} 2$ macrophages were significantly lower when the NOVA1 expression level increased in $\mathrm{T}$ cells, tumor cells, and stromal spindle cells (Fig. 2G-L). expression in tumor cells and $\mathrm{T}$ cells, and strong expression in stromal spindle cells $(m-o)$; an AGC case showing weak NOVA1 expression in tumor cells, T cells, and spindle cells $(p-r)$. Cells showing NOVA1 positivity or negativity are mixed with variable proportions in each case $(a-r)$. Images were captured at $\times 100$ or $\times 200$ magnification. B Representative cases of high $(a-e)$ or low $(f-$ j) densities of infiltrating $\mathrm{CD}^{+} \mathrm{T}$ cells, forkhead box P3 (FOXP3)positive regulatory $\mathrm{T}$ cells, $\mathrm{CD}^{+} 8^{+}$macrophages, $\mathrm{CD}_{163^{+}} \mathrm{M} 2$ macrophages, and myeloperoxidase (MPO)-positive neutrophils within the tumor microenvironment. $H \& E$ hematoxylin and eosin

\section{Association between NOVA1 expression in tumor cells, $T$ cells, and stromal spindle cells and clinicopathologic factors}

When the tumor invasion depth [which corresponds to the pathologic T (pT) category, from pT1 to pT4] increased, the proportion of weak NOVA1 expression also increased, and the proportion of strong expression decreased in tumor cells, T cells, and stromal spindle cells (Fig. 3A-C). When lymph node metastasis [which corresponds to the patho$\operatorname{logic} \mathrm{N}(\mathrm{pN})$ category, from $\mathrm{pN} 0$ to $\mathrm{pN} 3$ ] rose, the proportion of weak NOVA1 expression increased, and the 


\section{A}
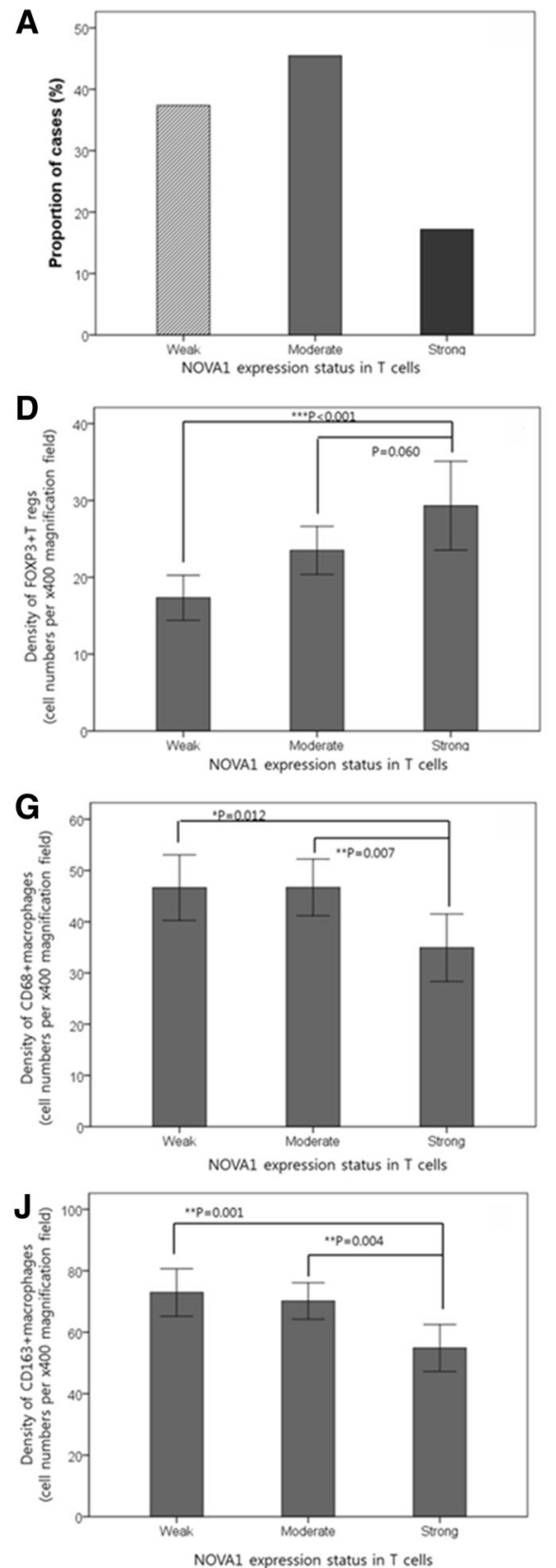

B
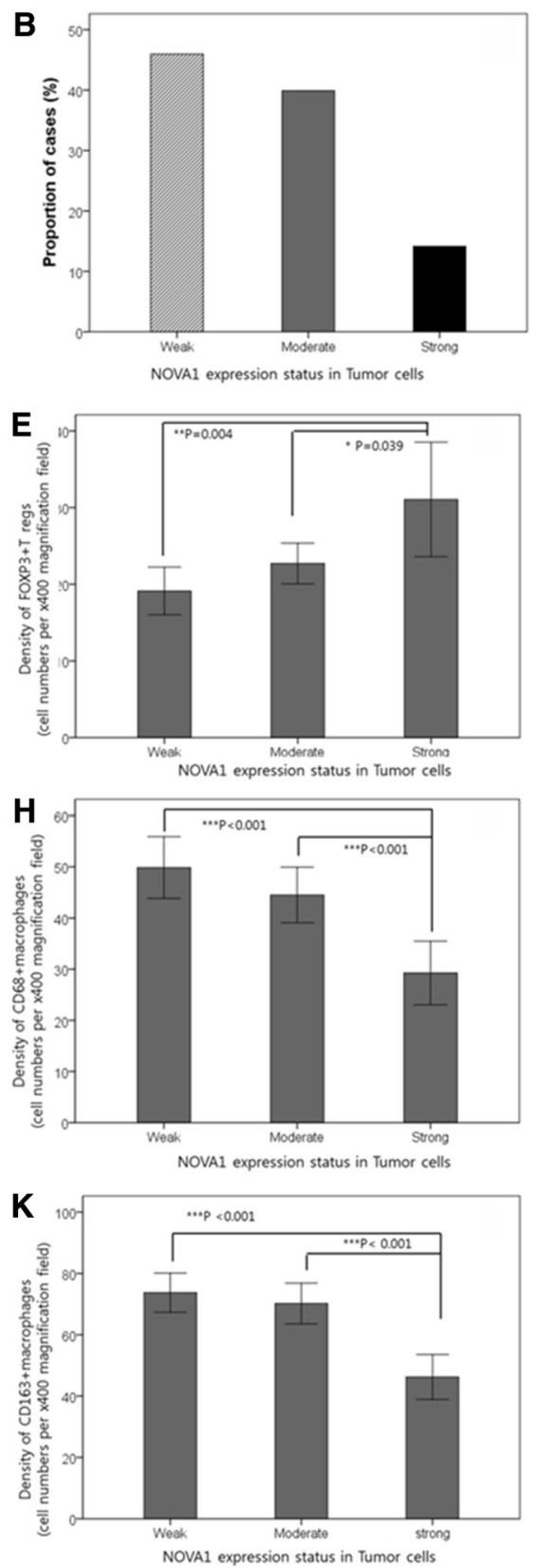
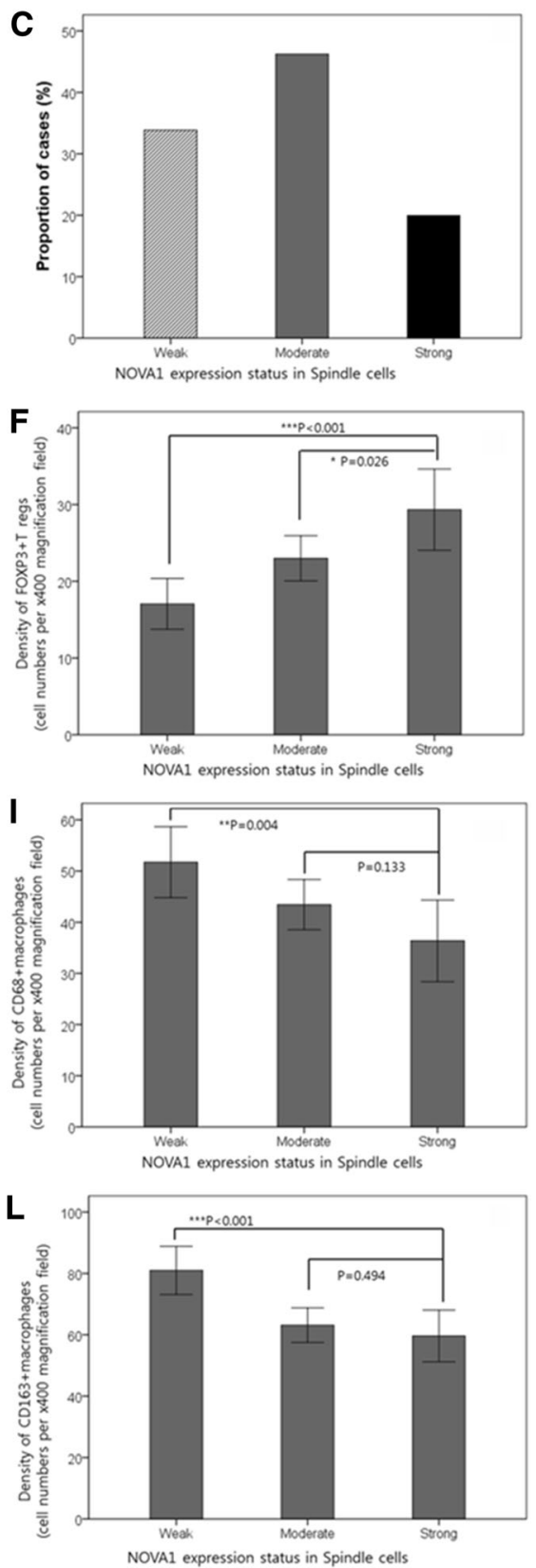

Fig. 2 Proportion of cases showing weak, moderate, or strong neurooncological ventral antigen 1 (NOVA1) expression in $\mathrm{T}$ cells $(\mathbf{A})$, tumor cells $(\mathbf{B})$, and stromal spindle cells $(\mathbf{C})$. Densities of forkhead box $\mathrm{P} 3$ positive $(F O X P 3+)$ regulatory $\mathrm{T}$ cells $(T$ regs $)$ are lower when NOVA1 expression is lower in T cells $(\mathbf{D})$, tumor cells $(\mathbf{E})$, and stromal spindle cells $(\mathbf{F})$. Densities of $\mathrm{CD}^{+} 8^{+}$macrophages and

proportion of strong expression decreased in tumor cells and stromal spindle cells, but not in T cells (Fig. 3D-F). Regarding the AJCC TNM stage, more advanced stages showed an increasing proportion of weak NOVA1 expression and a decreasing proportion of strong NOVA1 expression in tumor cells and stromal spindle cells, but not in T cells. Specifically, within the stage IV group, no cases had strong NOVA1 expression in tumor cells, T cells, or
$\mathrm{CD}_{163^{+}} \mathrm{M} 2$ macrophages are higher when NOVA1 expression is lower in T cells $(\mathbf{G}, \mathbf{J})$, tumor cells $(\mathbf{H}, \mathbf{K})$, and stromal spindle cells $(\mathbf{I}, \mathbf{L})$. The values shown in the histograms are the mean \pm the standard error. Statistically significant differences are indicated by one asterisk $(P<0.05)$, two asterisks $(P<0.005)$, and three asterisks $(P<0.001)$ as determined by ANOVA tests

stromal spindle cells (Fig. 3G-I). On multiple logistic regression analysis for the correlation between clinicopathologic factors and NOVA1 expression, weak NOVA1 expression in stromal spindle cells was independently associated with more advanced $\mathrm{pT}$ category (specifically pT3 and pT4), pN category (specifically pN3), and AJCC TNM stage (specifically stage III). Weak and moderate NOVA1 expression in tumor cells was associated with 

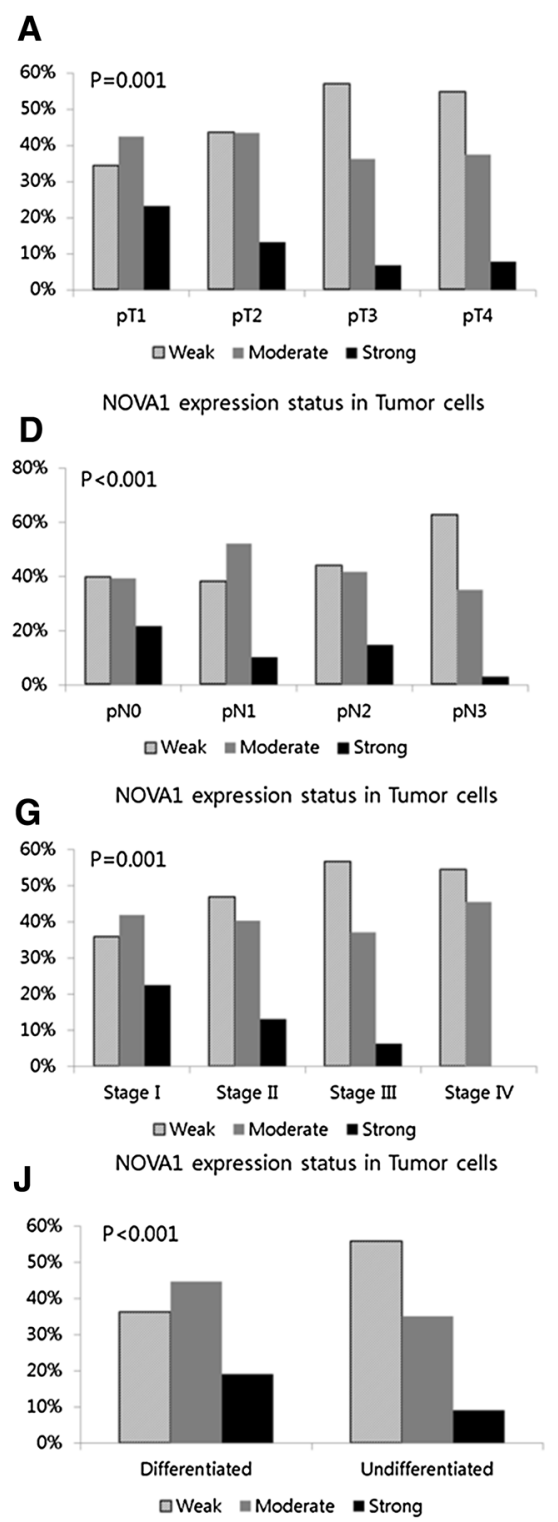

NOVAl expression status in Tumor cells
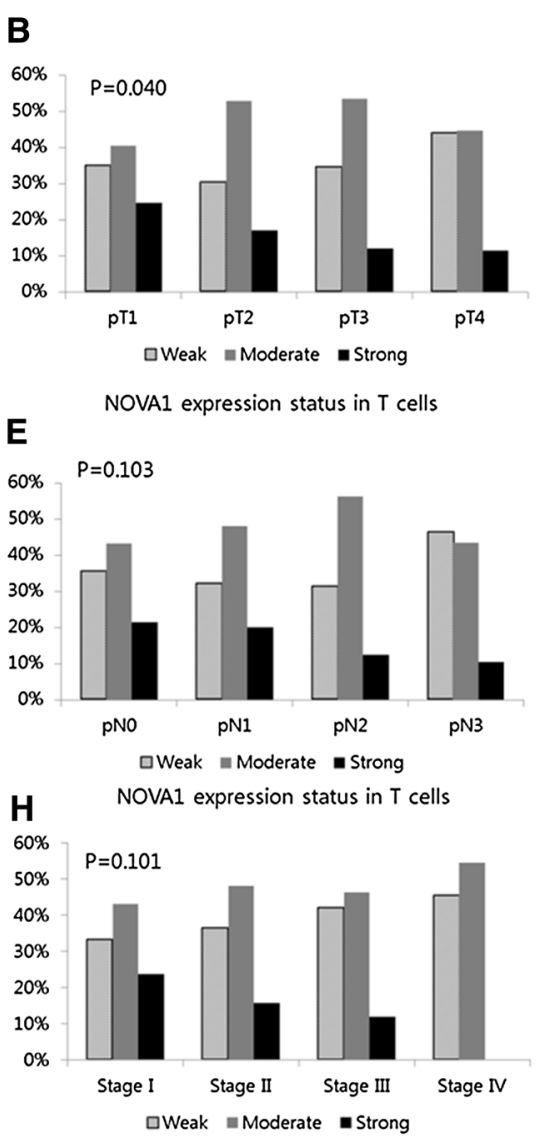

K NOVA1 expression status in T cells

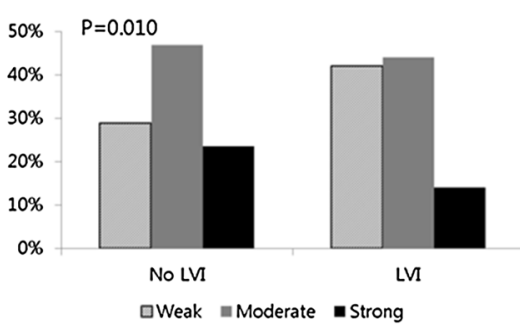

NOVA1 expression status in Spindle cells

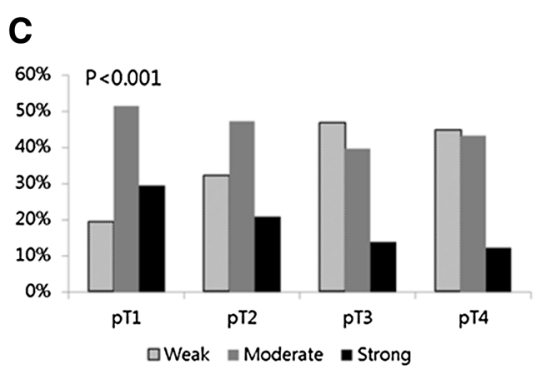

NOVA1 expression status in Spindle cells
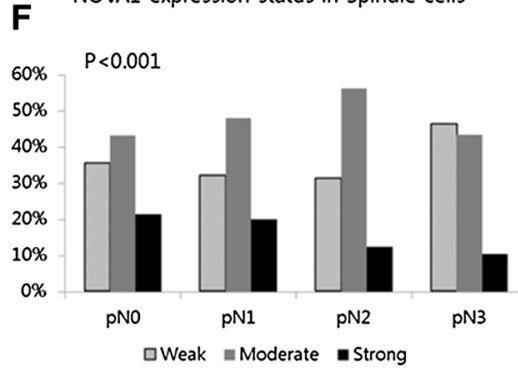

NOVA1 expression status in Spindle cells

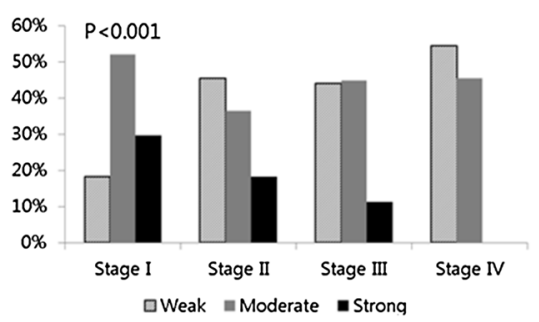

NOVA1 expression status in Spindle cells
Fig. 3 Proportions of pathologic T $(p T)$ category $(\mathbf{A}-\mathbf{C})$, pathologic $\mathrm{N}(p N)$ category $(\mathbf{D}-\mathbf{F})$, and American Joint Committee on Cancer TMN stage $(\mathbf{G}-\mathbf{I})$ cases according to neuro-oncological ventral antigen 1 (NOVA1) expression in tumor cells $(\mathbf{A}, \mathbf{D}, \mathbf{G})$, T cells $(\mathbf{B}, \mathbf{E}$, $\mathbf{H})$, and stromal spindle cells $(\mathbf{C}, \mathbf{F}, \mathbf{I})$. Association between histologic

more advanced $\mathrm{pN}$ category (specifically pN3) and AJCC stage (specifically stage III) (Table S2).

The proportion of weak NOVA1 expression increased in the case of undifferentiated histologic type when compared with differentiated histologic type in tumor cells (Fig. 3J), but not in T cells and stromal spindle cells $(P=0.086$ and $P=0.732$ respectively). For lymphovascular invasion, the proportion of strong expression decreased in stromal spindle cells (Fig. 3K), but not in tumor cells and $\mathrm{T}$ cells grade and NOVA1 expression of tumor cells $(\mathbf{J})$, and association between lymphovascular invasion and NOVA1 expression in stromal spindle cells $(\mathbf{K})$. The values shown in the histograms are case proportions (percentage) within each group. Statistically significant differences were determined by $\chi^{2}$ tests. LVI lymphovascular invasion

( $P=0.097$ and $P=0.096$ respectively). Patient-related factors such as age and sex were not significantly associated with NOVA1 expression in tumor cells, $\mathrm{T}$ cells, or stromal spindle cells (Table S2).

\section{Patient outcome according to NOVA1 expression}

In the Kaplan-Meier analysis for overall survival, attenuated (weak and moderate) NOVA1 expression in tumor 
A a

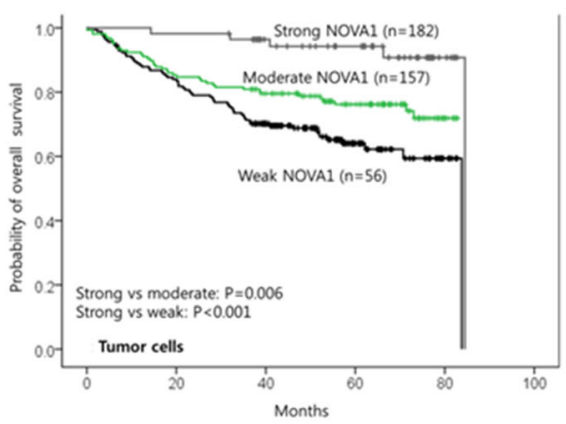

b

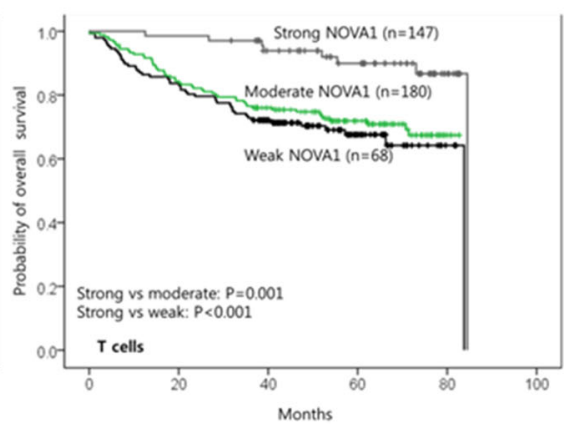

c

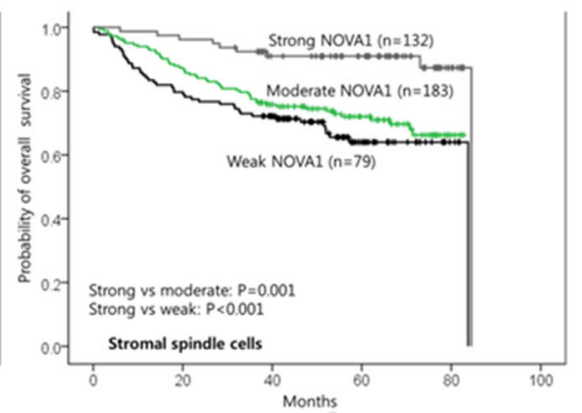

B a
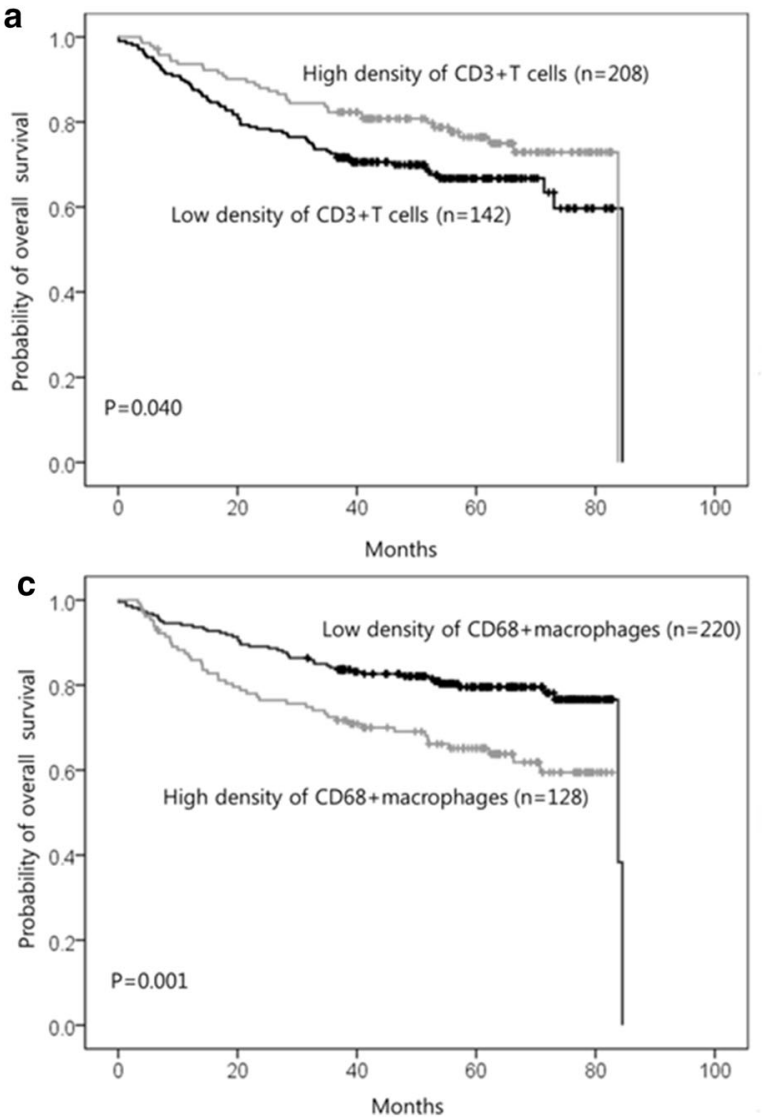

Fig. 4 A Strong neuro-oncological ventral antigen 1 (NOVA1) expression in tumor cells $(a)$, T cells $(b)$, and stromal spindle cells (c) was significantly related to a superior overall survival rate compared with attenuated (weak and moderate) expression. Information on survival was not clear in one case; therefore, overall survival was analyzed in 395 cases for which there was reliable information during the follow-up period. Survival function curves and survival rates were determined by the Kaplan-Meier method, and differences in survival rates were compared by the log-rank test. B High density of $\mathrm{CD}^{+} \mathrm{T}$ cells $(a)$ and forkhead box P3 positive (FOXP3+)

cells was significantly associated with inferior overall survival when compared with strong expression (Fig. 4A, plot a). Attenuated (weak and moderate) NOVA1 expression in $\mathrm{T}$ cells and stromal spindle cells within the microenvironment was also significantly associated with
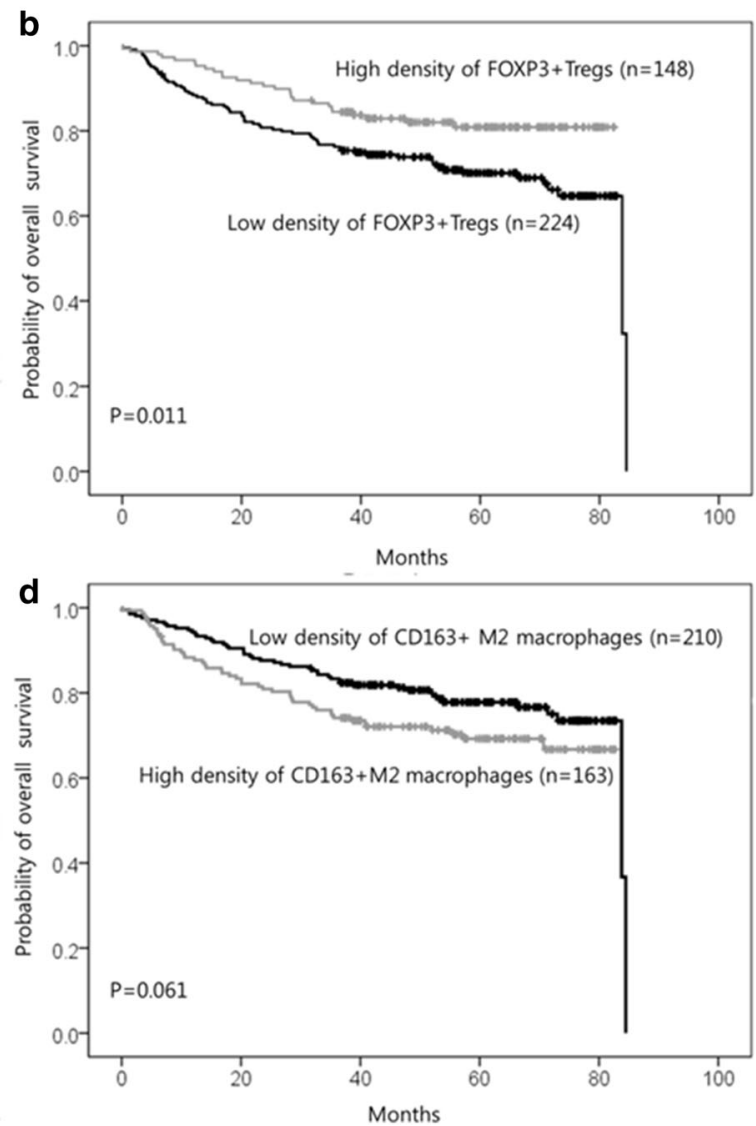

regulatory T cells (Tregs) (b) was related to superior overall survival rate, whereas a high density of $\mathrm{CD} 68^{+}$macrophages was related to an inferior overall survival rate $(c)$. A high density of $\mathrm{CD}_{163}{ }^{+} \mathrm{M} 2$ macrophages $(d)$ showed a tendency to be related to an inferior overall survival rate. Information on survival and/or immune cell infiltration was not clear in some cases; therefore, overall survival was analyzed in cases for which there was reliable information. Survival function curves and survival rates were determined by the KaplanMeier method, and differences in survival rates were compared by the log-rank test

inferior overall survival when compared with strong expression (Fig. 4A, plots b, c). According to the density of infiltrating immune cells within the tumor microenvironment, high densities (more than the mean value) of $\mathrm{CD}^{+} \mathrm{T}$ cells and $\mathrm{FOXP}^{+}$Tregs were significantly 
Table 2 Univariate and multivariate Cox analysis for overall survival

\begin{tabular}{|c|c|c|c|c|c|c|c|c|c|}
\hline \multirow[t]{3}{*}{ Variables } & \multirow[t]{3}{*}{ Category } & \multicolumn{4}{|c|}{ Univariate analysis } & \multicolumn{4}{|c|}{ Multivariate analysis } \\
\hline & & \multirow[t]{2}{*}{$P$} & \multirow[t]{2}{*}{ HR } & \multicolumn{2}{|c|}{$95 \% \mathrm{CI}$} & \multirow[t]{2}{*}{$P$} & \multirow[t]{2}{*}{ HR } & \multicolumn{2}{|c|}{$95 \% \mathrm{CI}$} \\
\hline & & & & $\begin{array}{l}\text { Lower } \\
\text { limit }\end{array}$ & $\begin{array}{l}\text { Upper } \\
\text { limit }\end{array}$ & & & $\begin{array}{l}\text { Lower } \\
\text { limit }\end{array}$ & $\begin{array}{l}\text { Upper } \\
\text { limit }\end{array}$ \\
\hline \multirow[t]{2}{*}{ Age (years) } & $\leq 60$ & & & & & & & & \\
\hline & $>60$ & 0.025 & 1.6 & 1.1 & 2.3 & 0.122 & 1.5 & 0.9 & 2.4 \\
\hline \multirow[t]{2}{*}{ Histologic type } & Differentiated & & & & & & & & \\
\hline & Undifferentiated & 0.002 & 1.9 & 1.3 & 2.8 & 0.161 & 1.6 & 0.8 & 2.9 \\
\hline \multirow[t]{2}{*}{ Lymphovascular invasion } & Absent & & & & & & & & \\
\hline & Present & $<0.001$ & 3.7 & 2.5 & 5.6 & 0.025 & 1.9 & 1.1 & 3.2 \\
\hline \multirow[t]{2}{*}{ Tumor location } & Nonhigh body & & & & & & & & \\
\hline & High body & 0.474 & 1.2 & 0.7 & 2.1 & & & & \\
\hline \multirow[t]{2}{*}{ pT category ${ }^{\mathrm{a}}$} & pT1-pT2 & & & & & & & & \\
\hline & pT3-pT4 & $<0.001$ & 6.9 & 4.1 & 11.8 & $<0.001$ & 5.3 & 2.3 & 12.0 \\
\hline \multirow[t]{2}{*}{ pN category ${ }^{\mathrm{a}}$} & pN0-pN1 & & & & & & & & \\
\hline & $\mathrm{pN} 2-\mathrm{pN} 3$ & $<0.001$ & 6.8 & 4.3 & 10.6 & 0.002 & 2.8 & 1.5 & 5.5 \\
\hline \multirow[t]{2}{*}{ Density of $\mathrm{CD}^{+} \mathrm{T}$ cells ${ }^{\mathrm{b}}$} & Low & & & & & & & & \\
\hline & High & 0.041 & 0.7 & 0.4 & 1.0 & 0.035 & 0.6 & 0.4 & 1.0 \\
\hline \multirow[t]{2}{*}{ Density of FOXP3 ${ }^{+}$Tregs $^{\mathrm{b}}$} & Low & & & & & & & & \\
\hline & High & 0.012 & 0.6 & 0.4 & 0.9 & 0.714 & 1.1 & 0.6 & 2.1 \\
\hline \multirow[t]{2}{*}{ Density of $\mathrm{CD} 68^{+}$macrophages ${ }^{\mathrm{b}}$} & Low & & & & & & & & \\
\hline & High & 0.001 & 2.0 & 1.3 & 3.0 & 0.883 & 1.0 & 0.6 & 1.6 \\
\hline \multirow[t]{2}{*}{ Density of $\mathrm{CD} 163^{+} \mathrm{M} 2$ macrophages $^{\mathrm{b}}$} & Low & & & & & & & & \\
\hline & High & 0.063 & 1.5 & 1.0 & 2.2 & & & & \\
\hline \multirow[t]{2}{*}{ Density of $\mathrm{MPO}^{+}$neutrophils ${ }^{\mathrm{b}}$} & Low & & & & & & & & \\
\hline & High & 0.443 & 0.9 & 0.6 & 1.3 & & & & \\
\hline \multirow[t]{2}{*}{ NOVA1 expression in tumor cells } & Strong & & & & & & & & \\
\hline & Attenuated $^{\mathrm{c}}$ & 0.001 & 5.3 & 1.9 & 14.3 & 0.018 & 11.0 & 1.5 & 80.9 \\
\hline \multirow[t]{2}{*}{ NOVA1 expression in T cells } & Strong & & & & & & & & \\
\hline & Attenuated $^{c}$ & 0.001 & 3.8 & 1.8 & 8.3 & 0.67 & 1.2 & 0.5 & 3.0 \\
\hline \multirow[t]{2}{*}{ NOVA1 expression in spindle cells } & Strong & & & & & & & & \\
\hline & Attenuated $^{c}$ & $<0.001$ & 3.7 & 1.8 & 7.7 & 0.245 & 1.9 & 0.7 & 5.2 \\
\hline
\end{tabular}

CI confidence interval, FOXP3 forkhead box P3, HR hazard ratio, MPO myeloperoxidase, NOVA1 neuro-oncological ventral antigen 1

${ }^{a}$ The stomach cancers were staged on the basis of the seventh edition of the AJCC Cancer Staging Manual [12].

b Infiltrating immune cell numbers per $\times 400$ magnification field

c "Attenuated" includes "moderate" and "weak."

correlated with superior overall survival (Fig. 4B, plots a, b), whereas a high density of $\mathrm{CD}^{+} 8^{+}$macrophages was significantly associated with inferior overall survival (Fig. 4B, plot c). A high density of $\mathrm{CD} 163^{+} \mathrm{M} 2$ macrophages showed a tendency toward correlation with inferior overall survival (Fig. 4B, plot d). The density of infiltrating neutrophils was not correlated with overall survival $(P=0.443)$. Among other clinicopathologic factors, age greater than 60 years $(P=0.024)$, undifferentiated histologic type $(P=0.001)$, lymphovascular invasion $(P<0.001)$, more advanced pT category $(P<0.001)$, and more advanced $\mathrm{pN}$ category $(P<0.001)$ were also associated with inferior overall survival . Tumor location (high body versus non-high body) was not related to the overall survival rate. On multivariate analysis, attenuated NOVA1 expression in tumor cells was independently associated with inferior overall survival (Table 2).

\section{Discussion}

We investigated the implications of NOVA1 expression in immune cell regulation within the cancer microenvironment. In addition, we examined the change of NOVA1 
expression within the cancer microenvironment according to tumor progression stage and patient outcome.

Strong NOVA1 expression in tumor cells, T lymphocytes, and stromal spindle cells was associated with favorable clinical outcomes in terms of tumor stage and overall survival, whereas attenuated (weak and moderate) expression was more related to poor clinical outcomes. In other words, when NOVA1 expression was lower in tumor cells, $\mathrm{T}$ cells, and stromal spindle cells, tumors invaded more deeply into the gastric wall, metastasized to more lymph modes, and were correlated with an inferior overall survival rate.

The close association between NOVA1 suppression and poor prognosis seems to be related to immune dysfunction. NOVA1 expression was not correlated with the density of overall infiltrating immune cells (lymphocytes, macrophages, and neutrophils) or infiltrating $\mathrm{T}$ cells. Since NOVA1 suppression was not related to T-cell depletion or paucity of overall immune cells, it may be related to changes in the immune surveillance function of the tertiary lymphoid structures. We found that NOVA1 expression was related to changes in immune cell composition; when its expression was attenuated in $\mathrm{T}$ cells, tumor cells, and stromal spindle cells, the density of $\mathrm{CD}^{+} 8^{+}$macrophages and $\mathrm{CD}_{163^{+}} \mathrm{M} 2$ macrophages increased, whereas the density of $\mathrm{FOXP}^{+}{ }^{+}$Tregs decreased. These findings suggest that NOVA1 suppression in cancer cells as well as microenvironment cells may be related to impaired function of Tregs. The prognostic value of infiltrating FOXP3 ${ }^{+}$ Tregs in the cancer microenvironment is inconsistent, and they are associated with poor prognosis or good prognosis in various cancer types, including gastric cancers [17, 18]. In the present study, the lower number of infiltrating $\mathrm{FOXP}^{+}$Tregs in the microenvironment was associated with poor prognosis.

As for tumor-associated macrophages, the antitumor or protumor activity of macrophages has been actively studied in several types of cancers. Specifically, CD163 ${ }^{+}$M2 macrophages are known to be associated with a tumorpromoting and immunosuppressive phenotype and are, therefore, associated with negative patient outcomes $[18,19]$. In the present study, a high number of $\mathrm{CD} 68^{+}$ macrophages within the gastric cancer microenvironment was associated with poor prognosis, and $\mathrm{CD}_{163}{ }^{+} \mathrm{M} 2$ macrophages also showed a tendency related to poor prognosis. NOVA1 suppression in cancer cells as well as microenvironment cells may be related to macrophage polarization toward a protumor, immunosuppressive phenotype.

In the present study, attenuated NOVA1 expression in tumor cells was determined to be an independent prognostic factor. Regarding the close correlation of NOVA1 expression status among tumor cells, $\mathrm{T}$ cells, and stromal spindle cells as shown in the present study as well as in our previous study [11], abnormal signaling may be primarily and independently induced by tumor cells, and this abnormal signaling may then secondarily deregulate microenvironment cells. Abnormal signaling molecules may affect the tumor cells themselves as well as the entire microenvironment cells, specifically $\mathrm{T}$ cells and stromal spindle cells, which normally show strong NOVA1 expression. In our previous study, miR-146b-5p was suggested to be an epigenetic signaling molecule that could inhibit NOVA1 [11]. In fact, several studies have shown that stromal cells such as cancer-associated fibroblasts or cancer-associated immune cells are epigenetically regulated within the tumor microenvironment through the microRNA signaling induced by tumor cells $[20,21]$. The secondarily induced NOVA1 suppression in spindle cells and $\mathrm{T}$ cells may result in abnormal tissue matrix function and immune regulation. In fact, stromal spindle cells actively regulate immune cells, as they are major components of tissue inflammation or tertiary lymphoid structures within the microenvironment [1-3]. Therefore, blocked NOVA1 function in these microenvironment cells may be related to immune escape of aggressive cancers. As a prognostic marker, the epigenetic regulation of NOVA1 may be used as a biomarker to predict patient prognosis and to evaluate the restoration of immune function of the tertiary lymphoid structures as well as tissue matrix function within the tumor microenvironment. We are planning a study of another gastric carcinoma cohort that extends beyond descriptive analysis.

In summary, NOVA1 suppression was frequently noted in the gastric cancer microenvironment and was associated with tumor progression and poor prognosis. Specifically, weak NOVA1 expression in tumor cells was independently related to more advanced tumor stage and inferior overall survival. This finding seems to be related to immune dysfunction through changes in the immune cell composition of $\mathrm{T}$ cells and macrophages.

Acknowledgment The study was supported by the Basic Science Research Program through the National Research Foundation of Korea funded by the Ministry of Education, Science and Technology (2012R1A1A2007344).

\section{Compliance with ethical standards}

Conflict of interest The authors have no conflicts of interest to declare.

Ethical approval All procedures performed in studies involving human participants were in accordance with the ethical standards of the institutional and/or national research committee and with the 1964 Helsinki declaration and its later amendments or comparable ethical standards. 
Informed consent For this type of study informed consent is not required.

\section{References}

1. Buckley CD, Barone F, Nayar S, Benezech C, Caamano J. Stromal cells in chronic inflammation and tertiary lymphoid organ formation. Annu Rev Immunol. 2015;33:715-45.

2. Dieu-Nosjean MC, Goc J, Giraldo NA, Sautes-Fridman C, Fridman WH. Tertiary lymphoid structures in cancer and beyond. Trends Immunol. 2014;35(11):571-80.

3. Di Caro G, Castino GF, Bergomas F, Cortese N, Chiriva-Internati $\mathrm{M}$, Grizzi F, et al. Tertiary lymphoid tissue in the tumor microenvironment: from its occurrence to immunotherapeutic implications. Int Rev Immunol. 2015;34(2):123-33.

4. Drayton DL, Liao S, Mounzer RH, Ruddle NH. Lymphoid organ development: from ontogeny to neogenesis. Nat Immunol. 2006;7(4):344-53.

5. Ruddle NH, Akirav EM. Secondary lymphoid organs: responding to genetic and environmental cues in ontogeny and the immune response. J Immunol. 2009;183(4):2205-12.

6. Barash Y, Calarco JA, Gao W, Pan Q, Wang X, Shai O, et al. Deciphering the splicing code. Nature. 2010;465(7294):53-9.

7. de la Grange P, Gratadou L, Delord M, Dutertre M, Auboeuf D. Splicing factor and exon profiling across human tissues. Nucleic Acids Res. 2010;38(9):2825-38.

8. Merkin J, Russell C, Chen P, Burge CB. Evolutionary dynamics of gene and isoform regulation in mammalian tissues. Science. 2012;338(6114):1593-9.

9. Kalsotra A, Cooper TA. Functional consequences of developmentally regulated alternative splicing. Nat Rev Genet. 2011;12(10):715-29.

10. Mallinjoud P, Villemin JP, Mortada H, Polay Espinoza M, Desmet FO, Samaan S, et al. Endothelial, epithelial, and fibroblast cells exhibit specific splicing programs independently of their tissue of origin. Genome Res. 2014;24(3):511-21.
11. Yoon SO, Kim EK, Lee M, Jung WY, Lee H, Kang Y et al. NOVA1 inhibition by miR-146b-5p in the remnant tissue microenvironment defines occult residual disease after gastric cancer removal. Oncotarget. 2016;7(3):2475-95.

12. Edge SB, Byrd DR., Compton CC, Fritz AG, Greene FL, Trotti A, editors. AJCC cancer staging manual. 7th ed. New York; London: Springer; 2010.

13. Bosman FT, Carneiro F, Hruban RH, Theise ND, editors. WHO classification of tumours of the digestive system. 4th ed. Lyon: International Agency for Research on Cancer; 2010.

14. Japanese Gastric Cancer Association. Japanese classification of gastric carcinoma: 3rd English edition. Gastric Cancer. 2011;14(2):101-12.

15. Kim H, Yoo SB, Sun P, Jin Y, Jheon S, Lee CT, et al. Alteration of the E-cadherin/ $\beta$-catenin complex is an independent poor prognostic factor in lung adenocarcinoma. Korean $\mathrm{J}$ Pathol. 2013;47(1):44-51.

16. Kim BH, Jung WY, Lee H, Kang Y, Jang YJ, Hong SW, et al. Lysyl-tRNA synthetase (KRS) expression in gastric carcinoma and tumor-associated inflammation. Ann Surg Oncol. 2014;21(6):2020-7.

17. deLeeuw RJ, Kost SE, Kakal JA, Nelson BH. The prognostic value of FoxP3 + tumor-infiltrating lymphocytes in cancer: a critical review of the literature. Clin Cancer Res. 2012;18(11):3022-9.

18. Lanca T, Silva-Santos B. The split nature of tumor-infiltrating leukocytes: implications for cancer surveillance and immunotherapy. Oncoimmunology. 2012;1(5):717-25.

19. Ruffell B, Coussens LM. Macrophages and therapeutic resistance in cancer. Cancer Cell. 2015;27(4):462-72.

20. Qiu W, Hu M, Sridhar A, Opeskin K, Fox S, Shipitsin M, et al. No evidence of clonal somatic genetic alterations in cancer-associated fibroblasts from human breast and ovarian carcinomas. Nat Genet. 2008;40(5):650-5.

21. Kohlhapp FJ, Mitra AK, Lengyel E, Peter ME. MicroRNAs as mediators and communicators between cancer cells and the tumor microenvironment. Oncogene. 2015;34(48):5857-68. 